\title{
Anthroposophic therapy for asthma: A two-year prospective cohort study in routine outpatient settings
}

\author{
Harald J Hamre' \\ Claudia MWitt ${ }^{2}$ \\ Gunver S Kienle' \\ Christof Schnürer ${ }^{3}$ \\ Anja Glockmann' \\ Renatus Ziegler ${ }^{4}$ \\ Stefan N Willich ${ }^{2}$ \\ Helmut Kiene' \\ 'Institute for Applied Epistemology \\ and Medical Methodology, Freiburg, \\ Germany; ${ }^{2}$ Institute of Social Medicine, \\ Epidemiology, and Health Economics, \\ Charité University Medical Center, \\ Berlin, Germany; ${ }^{3}$ Internal Medicine \\ Practice, A Fraenkel Centrum, \\ Badenweiler, Germany; ${ }^{4}$ Society \\ for Cancer Research, Arlesheim, \\ Switzerland
}

This article was published in the following Dove Press journal: Journal of Asthma and Allergy

23 November 2009

Number of times this article has been viewed
Background: Anthroposophic treatment for asthma includes special artistic and physical therapies and special medications.

Methods: We studied consecutive outpatients starting anthroposophic treatment for asthma under routine conditions in Germany. Main outcomes were average asthma severity (0-10, primary outcome); symptoms (1-4); and asthma-related quality of life at 12-month follow-up (Asthma Quality of Life Questionnaire [AQLQ] overall score, 1-7, for adults; KINDL Questionnaire for Measuring Health-Related Quality of Life in Children and Adolescents, asthma module, 0-100, for children) at 12-month follow-up.

Results: Ninety patients (54 adults, 36 children) were included. Anthroposophic treatment modalities used were medications ( $88 \%$ of patients, $n=79 / 90)$; eurythmy therapy $(22 \%)$; art therapy (10\%); and rhythmical massage therapy (1\%). Median number of eurythmy/art/massage sessions was 12 (interquartile range 10-20), median therapy duration was 120 days (84-184). From baseline to 12 -month follow-up, all outcomes improved significantly $(P<0.001$ for all comparisons). Average improvements were: average asthma severity 2.61 points ( $95 \%$ confidence interval CI: 1.90-3.32); cough 0.93 (95\% CI: 0.60-1.25); dyspnea 0.92 (95\% CI: 0.56-1.28); exertion-induced symptoms 0.95 (95\% CI: 0.64-1.25); frequency of asthma attacks 0.78 ( $95 \% \mathrm{CI}$ : 0.41-1.14); awakening from asthma 0.90 (95\% CI: 0.58-1.21); AQLQ overall score 1.44 (95\% CI: 0.97-1.92); and KINDL asthma module 14.74 (95\% CI: 9.70-19.78). All improvements were maintained until last follow-up after 24 months.

Conclusions: Patients with asthma under anthroposophic treatment had long-term improvements of symptoms and quality of life.

Keywords: anthroposophy, art therapy, asthma, combined modality therapy, drug therapy, eurythmy therapy, prospective studies, quality of life

\section{Background}

Asthma affects more than $10 \%$ of the population in developed countries ${ }^{1}$ and is associated with disability, reduced quality of life, reduced work capacity, psychiatric comorbidity, increased healthcare use, and increased mortality. ${ }^{2,3}$

Even under optimized guideline-based therapy in clinical trials, asthma symptoms remain poorly controlled in a proportion of patients, ${ }^{4,5}$ and many patients with asthma use complementary therapies, ${ }^{6}$ which are sometimes provided by their physicians.

Anthroposophic medicine (AM) is a complementary therapy system founded by Rudolf Steiner and Ita Wegman ${ }^{7}$ and provided by specially trained physicians in 56 countries worldwide. ${ }^{8}$ AM acknowledges a spiritual-existential dimension in man, which is assumed to interact with psychological and somatic levels in health
Correspondence: Harald J Hamre IFAEMM, Zechenweg 6, D-79III Freiburg, Germany Tel +497611560307 Fax +497611560306 Email harald.hamre@ifaemm.de 
and disease. AM therapy for asthma aims to counteract constitutional vulnerability, stimulate salutogenetic selfhealing capacities, and strengthen patient autonomy. ${ }^{9-14}$ The AM approach differs from conventional treatment in the use of special therapies (eurythmy movement exercises, art therapy, rhythmical massage therapy) and special medications.

Eurythmy therapy is an artistic exercise therapy involving cognitive, emotional and volitional elements. ${ }^{15}$ In eurythmy therapy sessions the patients are instructed to exercise specific movements with the hands, the feet or the whole body. Eurythmy movements are related to the sounds of vowels and consonants, to music intervals or to soul gestures, eg, sympathy-antipathy. A eurythmy therapy cycle usually consists of 12-15 sessions of $45 \mathrm{~min}$ each, administered once weekly. ${ }^{16}$ Between therapy sessions the patients exercise eurythmy movements daily. In AM art therapy the patients engage in painting, drawing, clay modeling, music or speech exercises. An AM art therapy cycle usually consists of 12 sessions of 45 min each, administered once weekly. ${ }^{17}$ Rhythmical massage therapy was developed from Swedish massage; special techniques include lifting movements, rhythmically undulating gliding movements, and complex movement patterns like lemniscates. A rhythmical massage therapy cycle usually consists of 6-12 sessions administered once or twice weekly, each session lasting 20-30 min and followed by a rest period of at least $20 \mathrm{~min} .{ }^{18}$ Most patients can be treated with one cycle of art, eurythmy or massage therapy, while prolonged treatment may be necessary for some patients with severe or persistent disease. AM medications are prepared from plants, minerals, animals, and from chemically defined substances. A key concept of AM medication therapy is typological correspondences between pathophysiological processes in man and formative forces working in minerals, plants and animals, reflecting a common evolution of man and nature. ${ }^{19}$ All AM medications are manufactured according to Good Manufacturing Practice and national drug regulations; quality standards of raw materials and manufacturing methods are described in the Anthroposophic Pharmaceutical Codex. ${ }^{20}$ The available evidence suggests that AM medications and therapies are generally well tolerated, with infrequent adverse reactions of mostly mild to moderate severity. ${ }^{21,22}$

Related to the AM approach is an educational philosophy implemented in more than 3,000 Waldorf Schools, kindergartens, and curative education centers worldwide. ${ }^{23,24}$ Waldorf school attendance has been associated with a reduced risk for atopy, ${ }^{25,26}$ possibly mediated by effects on the intestinal microflora from restrictive use of antibiotics and antipyretics in childhood infectious disease ${ }^{26}$ or from a diet containing fermented vegetables. ${ }^{27}$

AM therapy is provided by physicians (counseling, AM medication) and nonmedical therapists (eurythmy, art, rhythmical massage). For patients with asthma the physician will choose among the available AM therapy modalities in order to tailor the treatment to individual disease features and the patient's constitution. Initially, AM physicians will start AM treatment and optimize conventional therapy to achieve optimal symptom control. Subsequently, use of conventional medications may be slowly reduced while supervising controlling lung function. AM treatment will aim for optimal asthma control while keeping the use of conventional medication therapy as low as possible. ${ }^{13,14}$

A few mono- or bi-centric studies have evaluated AM medications ${ }^{28,29}$ or comprehensive AM therapy ${ }^{30,31}$ for asthma in inpatient hospitals, ${ }^{29,30}$ outpatient clinics, ${ }^{28,30,31}$ and practice settings. ${ }^{31}$ Here we present a pre-planned subgroup analysis of asthma patients from a multicenter study of comprehensive AM treatment in office-based settings. ${ }^{32}$

\section{Methods}

\section{Study design and objective}

This is a prospective cohort study in a real-world medical setting. The study was part of a research project on the effectiveness, costs, and safety of AM therapies in outpatients with chronic disease (Anthroposophic Medicine Outcomes Study [AMOS]). ${ }^{32,33}$ The AMOS project was initiated by a health insurance company in conjunction with a health benefit program. The present pre-planned analysis concerned the subgroup of patients treated for asthma. Since this was one of the first prospective studies of comprehensive AM treatment for this indication in a Western office-based multicenter setting, ${ }^{21}$ the primary objective was to describe the AM therapy (spectrum of AM therapy modalities used, extent of combination with conventional asthma therapy) as well as the clinical outcome under AM treatment. Further research questions addressed the use of health services, adverse reactions, and therapy satisfaction.

\section{Setting, participants, and therapy}

All physicians certified by the Physicians' Association for Anthroposophical Medicine in Germany and working in an office-based practice or outpatient clinic were invited to participate in the study. Certification as an AM physician required a completed medical degree and a three-year structured postgraduate training. The participating physicians recruited consecutive patients starting AM therapy. 
Patients enrolled in the period from January 1st, 1999 to December 31st, 2005 were included in the present analysis if they fulfilled the eligibility criteria. Inclusion criteria were:

1. Outpatients aged 2-70 years.

2. A clinical diagnosis of asthma (International Statistical Classification of Diseases and Related Health Problems, 10th revision [ICD-10] J45).

3. Starting AM therapy for asthma:

- AM-related consultation of at least 30 minutes followed by new prescription of AM medication,

- OR new referral to AM therapy (art, eurythmy, or rhythmical massage).

Patients were excluded if they had previously received the AM therapy in question for asthma. Patients were treated at the physicians' discretion; physicians were thus free to individualize treatment. AM treatment was evaluated as a whole system. ${ }^{34}$

\section{Clinical outcomes}

Primary outcome was average asthma severity, assessed on a numerical rating scale ${ }^{35}$ from 0 ("not present") to 10 ("worst possible"), at 12-month follow-up. A 12-month follow-up period was chosen for the primary outcome assessment to eliminate any seasonal symptom variation.

Secondary clinical outcomes were asthma symptoms, symptom score, and quality of life. Asthma symptoms in the past three months (at baseline: in the past 12 months) were assessed on Likert scales from 1 (no symptoms) to 4 (maximum symptoms) (adapted from Wjst and Wichmann ${ }^{36}$ and Weiland and colleagues $\left.{ }^{37}\right)$ :

- Cough, dyspnea, exertion-induced symptoms: "no", "little", "medium", "severe".

- Frequency of asthma attacks: "never", "up to once per month", "up to once per week", "several times weekly".

- Awakening from asthma at night: "never", "less than one night per week", "1-3 nights per week", " $\geq 4$ nights per week".

Symptom score, the severity of one to six most relevant symptoms present at baseline, was assessed on numerical rating scales ${ }^{35}$ from 0 ("not present") to 10 ("worst possible").

In adults aged 17-70 years, asthma-related quality of life was assessed with the Asthma Quality of Life Questionnaire (AQLQ).$^{38}$ The AQLQ comprises an overall score and the subscales activity limitations, symptoms, emotional function, and exposure to environmental stimuli. Each AQLQ score ranges from 1 (maximal impairment) to 7 (no impairment). AQLQ score changes are classified as minimally important
(0.5-1.0 points), moderate (1.0-1.5 points) and large ( $>1.5$ points). ${ }^{39}$ Generic quality of life in adults was assessed by the Short-Form, 36 question (SF-36 ${ }^{\circledR}$ ) Health Survey ${ }^{40}$ (physical and mental component summary measures).

In children aged 3-16 years, quality of life was assessed with the KINDL ${ }^{\circledR}$ Questionnaire for Measuring HealthRelated Quality of Life in Children and Adolescents ${ }^{41}$ (asthma module and total quality of life score, 0-100).

All clinical outcomes were documented by patients (or caregivers of children) on questionnaires after 0, 3, 6, 12, 18, and 24 months. Asthma symptoms, AQLQ, and KINDL were documented in patients enrolled after March 2001.

\section{Other outcomes}

Therapy outcome rating (0-10) and satisfaction with therapy $(0-10)$ were documented by patients or caregivers after six and 12 months.

Adverse reactions to medications or therapies were documented by the patients after six, 12, 18, and 24 months and by the physicians after six months. The documentation included suspected cause, intensity (mild, moderate, severe = no, some, complete impairment of normal daily activities), and therapy withdrawal because of adverse reactions. Serious adverse events (death, life-threatening condition, acute in-patient hospitalization, new disease or accident causing permanent disability, congenital anomaly, new malignancy) were documented by the physicians throughout the study. Adverse events and reactions occurring in patients enrolled until March 2001 were included in a detailed safety analysis of AM medications in the AMOS study. ${ }^{42}$

Use of adjunctive therapies and health services in the pre-study year was documented at study entry, use in the first study year was documented after six and 12 months, and use in the second study year was documented after 18 and 24 months. The following items were documented: physician or dentist visits, diagnostic investigations (X-rays, computer tomography, magnetic resonance imaging, scintigrams), non-AM medications, physiotherapy, psychotherapy, inpatient hospital and rehabilitation treatment, surgery, asthma-related surgery, and sick leave. Use of conventional asthma medication (Anatomical Therapeutic Chemical Classification Index H02, J01, J04, J07A, L03, R03, R06-07, see Table 1) in the pre-study year and in months $0-12$ was analyzed separately.

\section{Data collection}

All data were documented with questionnaires. Questionnaires used at study enrolment were handed out by the physicians; 
Table I Use of conventional asthma medication

\begin{tabular}{|c|c|c|c|c|c|c|}
\hline \multirow{3}{*}{$\begin{array}{l}\text { Medications (Anatomical Therapeutic } \\
\text { Chemical Classification Index) }\end{array}$} & \multicolumn{3}{|c|}{ Prestudy year } & \multicolumn{3}{|c|}{ Months 0-12 } \\
\hline & \multicolumn{2}{|c|}{ Patients } & \multirow[t]{2}{*}{ Total days } & \multicolumn{2}{|c|}{ Patients } & \multirow[t]{2}{*}{ Total days } \\
\hline & $\mathbf{N}$ & $\%$ & & $\mathbf{N}$ & $\%$ & \\
\hline Any asthma medication & 38 & $72 \%$ & 12,215 & 31 & $58 \%$ & $1 \mathrm{I}, 278$ \\
\hline - H02 Corticosteroids for systemic use & 5 & $9 \%$ & 457 & 2 & $4 \%$ & 8 \\
\hline - J0I Antibacterials for systemic use & 7 & $13 \%$ & 344 & 4 & $8 \%$ & 48 \\
\hline - R03A Adrenergics, inhalants & 25 & $47 \%$ & 4,322 & 28 & $53 \%$ & 4,762 \\
\hline - R03BA Glucocorticoids & 12 & $23 \%$ & 3,214 & 16 & $30 \%$ & 4,012 \\
\hline - R03BB Anticholinergics & 0 & $0 \%$ & 0 & I & $2 \%$ & 120 \\
\hline - R03BC Antiallergic agents & 7 & $13 \%$ & 1,019 & 5 & $9 \%$ & 640 \\
\hline - R03C Adrenergics for systemic use & I & $2 \%$ & 90 & 0 & $0 \%$ & 0 \\
\hline $\begin{array}{l}\text { - R03D Other systemic drugs for } \\
\text { obstructive airway diseases }\end{array}$ & 10 & $19 \%$ & 2,278 & 10 & $19 \%$ & 2,204 \\
\hline - R06 Antihistamines for systemic use & 7 & $13 \%$ & 491 & 7 & $13 \%$ & 220 \\
\hline - Other: J04, J07A, L03, R03BX & 0 & $0 \%$ & 0 & 0 & $0 \%$ & 0 \\
\hline No asthma medication & 15 & $28 \%$ & 0 & 22 & $42 \%$ & 0 \\
\hline Total (evaluable patients) & 53 & $100 \%$ & & 53 & $100 \%$ & \\
\hline
\end{tabular}

Notes: Evaluable patients: patients with evaluable data on medication use at baseline and at 3-, 6-, and I2-month follow-up.

follow-up questionnaires were administered from the study office by post. All questionnaires were returned in sealed envelopes to the study office. Physicians documented eligibility criteria; all other items were documented by patients (by caregivers of children $<17$ years) unless otherwise stated. The patient responses were not made available to the physicians. Medication use was documented with name of medication, administration frequency (daily, 3-6 days per week, 1-2 days per week, 1-3 days per month, $<1$ day per month), and duration of use.

The physicians were compensated $€ 40$ (after March 2001: $€ 60)$ per included and fully documented patient, while the patients received no financial compensation.

The data were entered twice by two different persons into Microsoft ${ }^{\circledR}$ Access 97 (Microsoft Corp., Redmond, WA, USA). The two datasets were compared and discrepancies resolved by checking with the original data.

\section{Quality assurance, adherence}

\section{to regulations}

The study was approved by the Ethics Committee of the Faculty of Medicine Charité, Humboldt University, Berlin, Germany, and was conducted according to the Declaration of Helsinki and largely following the ICH Guidelines for Good Clinical Practice E6. Written informed consent was obtained from all patients before enrolment.

\section{Data analysis}

The data analysis was performed on all patients fulfilling the eligibility criteria, using SPSS ${ }^{\circledR} 17.0$ (SPSS Inc., Chicago, Ill, USA) and StatXact ${ }^{\circledR}$ 5.0.3 (Cytel Software Corporation, Cambridge, MA, USA). For univariate comparisons of continuous data with normal distribution t-test for paired samples was used for paired samples and t-test for independent samples was used for independent samples; Wilcoxon signedrank test was used for paired continuous data with nonnormal distribution; McNemar test and Fisher's exact test were used for dichotomous data. All tests were two-tailed. Clinical outcomes were analyzed with 0-12 month and 0-24 month pre-post comparisons. In addition, repeated measures analysis of variance (ANOVA) was performed, testing for within-subject change between the time points $0-3-6-12$ months and 0-18-24 months, respectively. If Mauchly's test of sphericity was significant, Greenhouse-Geisser epsilon adjustment was performed. ${ }^{43}$ Significance criterion was $P<0.05$. Since this was a descriptive study, no adjustment for multiple comparisons was performed.$^{44}$ Pre-post effect sizes were calculated as standardized response mean (= mean change score divided by the standard deviation of the change score) and classified as minimal $(<0.20)$, small $(0.20-0.49)$, medium $(0.50-0.79)$, and large $(\geq 0.80) .{ }^{45,46}$ In the main analysis, clinical outcomes were analyzed in patients with evaluable data for each follow-up, without replacement of missing values. 
Two pre-planned sensitivity analyses (SA1-SA2) were performed to assess the influence of patient attrition (SA1) and conventional antiasthma therapies (SA2) on the 0-12-month outcome of average asthma severity. In SA1 missing values after 12 months were replaced with the last value carried forward. In SA2 the sample was restricted to patients not using conventional asthma medications except adrenergic inhalants and not having asthma-related surgery during the first 12 study months. Post-hoc subgroup analyses were performed on evaluable subgroups (age, AM therapy modality, number of patients enrolled per physician).

\section{Results}

\section{Participating physicians and therapists}

The patients were enrolled by 36 physicians ( 26 general practitioners, eight pediatricians, and two internists). Comparing these physicians to AM-certified physicians in Germany with the same qualifications but without study patients $(n=311)$, no significant differences were found regarding age (mean \pm standard deviation: $46.5 \pm 6.7$ vs $48.3 \pm 8.1$ years), gender $(72.2 \%$ vs $58.8 \%$ male), number of years in practice (17.3 \pm 7.0 vs $19.3 \pm 8.8$ years) or the proportion of primary care physicians ( $94.4 \%$ vs $94.4 \%$ ).

The patients were treated by 31 different AM therapists (art, eurythmy, rhythmical massage). Comparing these therapists to certified AM therapists in Germany without study patients $(\mathrm{n}=1137)$, no significant differences were found regarding gender $(71.0 \%$ vs $81.4 \%$ females), age (mean $50.2 \pm 7.8$ vs $50.2 \pm 9.5$ years) or the number of years since therapist qualification (13.8 \pm 6.9 vs $13.1 \pm 8.7$ years $)$.

\section{Patient recruitment and follow-up}

A total of 95 patients starting AM therapy for asthma were assessed for eligibility. Of these patients, 90 fulfilled all eligibility criteria and were included in the analysis. Five patients were not included, for the following reasons: patients' and physicians' baseline questionnaire dated $>30$ days apart $(\mathrm{n}=4)$, no informed consent $(\mathrm{n}=1)$.

A total of $44 \%(n=40 / 90)$ of patients were enrolled by general practitioners, $41 \%(n=37)$ by internists, and $14 \%(n=13)$ by pediatricians. The physicians' settings were primary care practices $(53 \%$ of evaluable patients, $n=47 / 88)$, referral practices $(41 \%, n=36)$, and outpatient clinics $(6 \%, n=5)$. A total of 31 physicians enrolled 1-2 patients each, four physicians enrolled 3-5 patients each, and one physician specializing in AM asthma therapy enrolled 36 patients.

The last patient follow-up ensued on November 10th, 2007. A total of $92 \%(n=83 / 90)$ of patients returned at least one follow-up questionnaire. The patients were administered a total of 450 questionnaires, out of which 324 (72\%) were returned. Follow-up rates were $83 \%(\mathrm{n}=75 / 90), 72 \%$ $(\mathrm{n}=65), 74 \%(\mathrm{n}=67), 64 \%(\mathrm{n}=58)$, and $66 \%(\mathrm{n}=59)$ after $3,6,12,18$, and 24 months, respectively. Respondents and nonrespondents of the 12-month patient-follow-up did not differ significantly regarding age, gender, disease duration or baseline parameters (average asthma severity, symptom score, AQLQ overall score). Comparisons of respondents $(n=43)$ and nonrespondents $(n=18)$ of the 24-month follow-up also showed no significant differences for these parameters. The physician six-month follow-up documentation was available for $89 \%(n=80 / 90)$ of patients.

\section{Numbers analyzed}

The numbers analyzed for major subgroups and follow-up periods are presented in Table 2 .

\section{Baseline characteristics}

The patients were recruited from nine of 16 German federal states. The sample comprised 36 children (aged 2-16 years) and 54 adults (aged 18-68 years). Age groups were $2-19$ years $(41 \%, \mathrm{n}=37 / 90), 20-39$ years $(21 \%, \mathrm{n}=19), 40-59$ years $(31 \%, \mathrm{n}=28)$, and $60-70$ years $(7 \%, \mathrm{n}=6)$ with a median age of 33.8 years (interquartile range [IQR] 9.2-44.8 years, range $2-68$ years, mean $29.5 \pm 19.5$ years $)$. A total of $36 \%(n=13 / 36)$ of the children and $70 \%(n=38 / 54)$ of the adults were women.

Compared with the German population, adult patients had higher educational and occupational levels and were less frequently unemployed, living alone, regular smokers, and daily alcohol consumers; sociodemographic status was similar to the population regarding the proportion with overweight or living on a low income as well as work disability pension and severe disability status; while the number of sick-leave days in the past year was higher in study patients than in the population (Table 3).

The disease duration was $<1$ year in $6 \%(\mathrm{n}=5 / 90)$ of patients, $1-4$ years in $37 \%(\mathrm{n}=33)$, and $\geq 5$ years in $58 \%(\mathrm{n}=52)$, with a median disease duration of 5.0 (IQR $1.0-10.0$ years, mean $10.1 \pm 10.6$ years). A total of $96 \%$ $(n=52 / 54)$ of adults had a disease duration of $\geq 1$ year.

A current comorbid disease was present in $81 \%(\mathrm{n}=73 / 90)$ of patients, with a median of 1 (IQR 1-3) comorbid diseases per patient. Most common comorbid diseases, classified by ICD-10, were J30 vasomotor and allergic rhinitis (15.9\%, $\mathrm{n}=23$ of 145 diagnoses), J32 chronic sinusitis (7.6\%), and L20 atopic dermatitis (7.6\%). 
Table 2 Numbers analyzed

\begin{tabular}{|c|c|c|c|c|c|c|}
\hline \multirow[t]{2}{*}{ Patient group } & \multicolumn{2}{|c|}{ Month 0} & \multicolumn{2}{|c|}{ Month I 2 (Table 5) } & \multicolumn{2}{|c|}{ Month 24 (Table 7) } \\
\hline & $\mathbf{N}$ & Analysis & $\mathbf{N}^{*}$ & Analysis & $\mathbf{N}^{*}$ & Analysis \\
\hline All patients & 90 & $\begin{array}{l}\text { Disease status at } \\
\text { baseline (text) }\end{array}$ & 67 & $\begin{array}{l}\text { Average asthma severity } \\
\text { (see also Table 6), } \\
\text { symptom score }\end{array}$ & 59 & $\begin{array}{l}\text { Average asthma } \\
\text { severity, symptom } \\
\text { score }\end{array}$ \\
\hline All patients & & & 53 & $\begin{array}{l}\text { [Months } 3+6+12] \text { Use } \\
\text { of conventional asthma } \\
\text { medication (Table I) }\end{array}$ & & \\
\hline $\begin{array}{l}\text { Adults } \\
\text { (aged 18-68 years) }\end{array}$ & 54 & $\begin{array}{l}\text { Sociodemographics } \\
\text { (Table 3) }\end{array}$ & 38 & SF-36 & 35 & SF-36 \\
\hline $\begin{array}{l}\text { Children } \\
\text { (aged 2-16 years) }\end{array}$ & 36 & & & & & \\
\hline $\begin{array}{l}\text { Patients recruited } \\
\text { after March 200I }\end{array}$ & 65 & $\begin{array}{l}\text { Disease status at } \\
\text { baseline (Table 4) }\end{array}$ & & Asthma symptoms & & Asthma symptoms \\
\hline $\begin{array}{l}\text { Adults recruited } \\
\text { after March } 2001\end{array}$ & 42 & & 26 & AQLQ & 25 & AQLQ \\
\hline $\begin{array}{l}\text { Children recruited } \\
\text { after March 200I }\end{array}$ & 23 & & 16 & KINDL & 15 & KINDL \\
\hline
\end{tabular}

Abbreviations: $\mathrm{N}^{*}$, refers to number of patients returning the respective follow-up questionnaire; the corresponding number with evaluable data for an individual outcome may be lower; AQLQ, Asthma Quality of Life Questionnaire; KINDL, Questionnaire for Measuring Health-Related Quality of Life in Children and Adolescents; SF-36, ShortForm Health Survey (36 items).

Further baseline data on asthma were documented in patients enrolled after March 2001 (Table 4): A total of 56\% $(n=35 / 62)$ of these patients had only intermittent symptoms with asthma attacks $\leq$ once per month and awakening from asthma $<1$ night per week.

\section{Therapy}

At study enrolment, the duration of the consultation with the AM physician was $<30 \mathrm{~min}$ in $24 \%(\mathrm{n}=22 / 90)$ of patients, $30-44 \mathrm{~min}$ in $31 \%, 45-59 \mathrm{~min}$ in $29 \%$, and $\geq 60 \mathrm{~min}$ in $16 \%$ of patients. At enrolment $60 \%(n=54 / 90)$ of patients were prescribed AM medication by the physician, while the remaining $40 \%(n=36)$ were referred to eurythmy therapy, AM art therapy, or rhythmical massage therapy (eurythmy/ art/massage therapy). Of these 36 patients, $83 \%(n=30)$ had the planned AM therapy, 3\% $(n=1)$ did not have AM therapy, and for $14 \%(n=5)$ the AM therapy documentation is incomplete. AM therapies used were eurythmy therapy ( $n=20)$, rhythmical massage therapy $(n=1)$, and AM art therapy $(\mathrm{n}=9)$ with the therapy modalities painting/drawing/ clay $(n=4)$, music $(n=3)$, and speech exercises $(n=2)$. The AM eurythmy/art/massage therapy started median 14 (IQR 0-32) days after enrolment. Median therapy duration was 120 days (IQR 84-184 days), median number of therapy sessions was 12 (IQR 10-20). AM medications were used by $88 \%(n=79 / 90)$ of patients. The most frequently used AM medications in month 0-12 (different dosage forms and concentrations grouped together) were Heracleum mantegazzianum ( $\mathrm{n}=31$ patients), Tabacum Cupro cultum $(\mathrm{n}=31)$, Quartz $(\mathrm{n}=30)$, Tartarus stibiatus $(\mathrm{n}=11)$, Argentum/Echinacea $(\mathrm{n}=10)$, and Gencydo $(\mathrm{n}=10)$.

The use of adjunctive therapies, health services, and sick leave was compared between the pre-study year and the first and second years, respectively. One significant change was found: The number of physician/dentist visits decreased from average $20.6 \pm 52.4$ visits in the pre-study year to $12.2 \pm 17.1$ visits in the first year $(P=0.001)$ and $12.5 \pm 12.7$ visits in the second year $(P=0.001)$. No other items (non-AM medications, physiotherapy, psychotherapy, diagnostic investigations, inpatient hospital or rehabilitation treatment, surgery or sick leave) changed significantly in any period.

The use of conventional asthma therapy in the pre-study year and in months $0-12$ was analyzed separately. Conventional asthma medications were used by $72 \%$ $(\mathrm{n}=38 / 53)$ of evaluable patients in the pre-study year, and by $58 \%(\mathrm{n}=31 / 53)$ in months $0-12(P=0.039)$. The most frequently used medications in months $0-12$, classified by the Anatomical Therapeutic Chemical Classification Index, were R03A adrenergics, inhalants ( $53 \%, \mathrm{n}=28 / 53$ patients), R03BA glucocorticoids $(30 \%, \mathrm{n}=16 / 53)$. Further data on conventional asthma medications are presented in Table 1. Asthma-relevant surgery occurred in one patient in the pre-study year and in one patient in months 0-12 (nasal polyp surgery in both cases). 
Table 3 Sociodemographic data of adult patients

\begin{tabular}{|c|c|c|c|c|c|}
\hline \multirow[t]{2}{*}{ Item } & \multirow[t]{2}{*}{ Subgroups } & \multicolumn{2}{|c|}{ Study patients } & \multirow{2}{*}{$\frac{\text { German population }}{\%}$} & \multirow[t]{2}{*}{ References } \\
\hline & & $\mathbf{N}$ & $\%$ & & \\
\hline \multirow[t]{3}{*}{ Education $^{72}$} & Low (level I ) & $6 / 54$ & $11 \%$ & $43 \%$ & \multirow[t]{3}{*}{73} \\
\hline & Intermediate (level 2) & $25 / 54$ & $46 \%$ & $43 \%$ & \\
\hline & High (level 3) & $23 / 54$ & $43 \%$ & $14 \%$ & \\
\hline Wage earners & Economically active patients & $1 / 36$ & $3 \%$ & $18 \%$ & 74 \\
\hline Unemployed during last 12 months & Economically active patients & $0 / 36$ & $0 \%$ & $10 \%$ & 74 \\
\hline Living alone & & $7 / 54$ & $13 \%$ & $21 \%$ & 74 \\
\hline Net family income $<€ 900$ per month & & $4 / 46$ & $9 \%$ & $16 \%$ & 74 \\
\hline \multirow{2}{*}{$\begin{array}{l}\text { Alcohol use daily (patients) vs almost } \\
\text { daily (Germany) }\end{array}$} & Male & $1 / 16$ & $6 \%$ & $28 \%$ & \multirow[t]{2}{*}{75} \\
\hline & Female & $1 / 38$ & $3 \%$ & $11 \%$ & \\
\hline \multirow[t]{2}{*}{ Regular smoking } & Male & $2 / 16$ & $13 \%$ & $37 \%$ & \multirow[t]{2}{*}{76} \\
\hline & Female & $2 / 38$ & $5 \%$ & $28 \%$ & \\
\hline Sports activity $\geq$ I hour weekly & Age $25-69$ years & $25 / 50$ & $50 \%$ & $39 \%$ & 77 \\
\hline \multirow[t]{2}{*}{ Body mass index $\geq 25$ (overweight) } & Male & $7 / 16$ & $44 \%$ & $56 \%$ & \multirow[t]{2}{*}{74} \\
\hline & Female & $15 / 37$ & $41 \%$ & $39 \%$ & \\
\hline Permanent work disability pension & & $4 / 54$ & $7 \%$ & $3 \%$ & 78 \\
\hline Severe disability status & & $5 / 54$ & $9 \%$ & $12 \%$ & 79 \\
\hline $\begin{array}{l}\text { Sick leave days in the last } 12 \text { months } \\
\text { (mean } \pm S D)\end{array}$ & Economically active patients & $29.2 \pm 38.3$ & & 17.0 & 80 \\
\hline
\end{tabular}

Abbreviation: SD, standard deviation.

\section{Clinical outcomes}

In months $0-12$ all 16 clinical outcomes improved significantly from baseline in the 0-12 month prepost comparison as well as in the 0-3-6-12 month ANOVA (Table 5). Most improvements occurred in months 0-6 (Figures 1-5). At 12 -month follow-up an improvement of $\geq 50 \%$ of baseline average asthma severity was observed in 59\% $(n=39 / 66)$ of evaluable patients; in adults the AQLQ overall score showed a minimally important improvement of $0.5-1.0$ points in $20 \%(\mathrm{n}=5 / 25)$ of evaluable patients, a moderate improvement of $1.0-1.5$ points in $28 \%(n=7)$, and a large improvement of $>1.5$ points in $38 \%(n=9)$. Standardized response mean effect sizes for the $0-12$ month comparison were large for 10 scores, medium for two, and small for one score (Table 5).

Subgroup analyses of the $0-12$ month pre-post comparison of average asthma severity (Table 6) showed significantly more improvement in children than in adults (mean difference 1.69 points, 95\% confidence interval [CI]: $0.31-3.07 ; P=0.017$ ). No significant difference in improvement was found between patients enrolled for medical therapy or referred to eurythmy/art/massage therapy ( $P=0.214)$ or when patients were grouped according to the number of patients enrolled per physician (1-5 patients vs 36 patients: $P=0.551$ ).
We performed two sensitivity analyses of the 0 -12-month outcome of average asthma severity (Table 6: SA1-SA2; see Methods for further description). SA1 alone resulted in a reduction of the average improvement of $13 \%(2.61 \rightarrow 2.28$ points) while SA2 alone and SA1+SA2 in combination had only minimal effects.

In months 18-24, a total of 14 of the 16 clinical outcomes were significantly improved from baseline in the $0-24$ month pre-post comparison as well as in the 0-18-24 month ANOVA, SF-36 mental component was significantly improved in the 0-18-24 month ANOVA only, and KINDL total score ( $\mathrm{n}=12$ patients) was not improved in any analysis (Table 7).

\section{Other outcomes}

At six-month follow-up, patients' therapy outcome rating (numeric scale from 0 "no help at all" to 10 "helped very well") was average $7.54 \pm 2.44$ and patient satisfaction with therapy (from 0 "very dissatisfied" to 10 "very satisfied") was $8.19 \pm 2.12$. The ratings of therapy outcome and satisfaction did not differ significantly between adults (patient rating) and children (proxy rating by caregivers) nor between six- and 12-month follow-up.

The frequency of reported adverse drug reactions was $6 \%$ ( $n=5$ of 79 users) for reactions with a suspected relation to 
Table 4 Disease status at baseline

\begin{tabular}{|c|c|c|}
\hline Item & $\mathbf{N}$ & $\%$ \\
\hline Asthma diagnosis definite & $64 / 65$ & $98 \%$ \\
\hline $\begin{array}{l}\text { Asthma diagnosis based on pulmonary } \\
\text { function tests or examination by } \\
\text { pulmonologist }\end{array}$ & $60 / 65$ & $92 \%$ \\
\hline \multicolumn{3}{|l|}{ Associated diseases (ever had) } \\
\hline Allergic rhinitis & $34 / 61$ & $56 \%$ \\
\hline Atopic dermatitis & $21 / 59$ & $36 \%$ \\
\hline Other allergic disease & $38 / 62$ & $61 \%$ \\
\hline \multicolumn{3}{|l|}{ Symptoms in past 12 months } \\
\hline Wheeze & $51 / 61$ & $84 \%$ \\
\hline Dry cough at night & $46 / 62$ & $74 \%$ \\
\hline Difficulty breathing & $43 / 61$ & $70 \%$ \\
\hline Wheeze on exertion & $47 / 61$ & $77 \%$ \\
\hline Seasonal asthma symptoms (yes) & $44 / 62$ & $71 \%$ \\
\hline \multicolumn{3}{|l|}{ Frequency of asthma attacks in past } \\
\hline \multicolumn{3}{|l|}{12 months } \\
\hline$\leq$ once per month & $39 / 62$ & $63 \%$ \\
\hline Sonce weekly & $6 / 62$ & $10 \%$ \\
\hline$\geq$ several times weekly & $17 / 62$ & $27 \%$ \\
\hline \multicolumn{3}{|l|}{ Awakening from asthma attacks at night } \\
\hline$<$ I night per week & $39 / 62$ & $63 \%$ \\
\hline I-3 nights per week & $10 / 62$ & $16 \%$ \\
\hline$\geq 4$ nights per week & $13 / 62$ & $21 \%$ \\
\hline $\begin{array}{l}\text { Emergency room or inpatient treatment } \\
\text { for asthma in past } 12 \text { months }\end{array}$ & $8 / 62$ & $13 \%$ \\
\hline CES-D $\geq 24$ points $=$ depressive range & $12 / 52$ & $23 \%$ \\
\hline
\end{tabular}

Notes: These items were documented in patients enrolled after March $200 \mathrm{I}(\mathrm{n}=65)$. Asthma diagnosis documented by physicians, other items by patients or caregivers. Abbreviations: CES-D, Center for Epidemiological Studies Depression Scale, German version. ${ }^{71}$

AM medications and $24 \%(n=16$ of 67 users $)$ for reactions with a suspected relation to non-AM medications $(P=0.004)$. Adverse drug reactions of severe intensity were reported in five patients (AM medications: $\mathrm{n}=1$, non-AM medications: $\mathrm{n}=4$ ), while medication was stopped due to reported adverse drug reactions in eight patients (AM medications: $n=2$, non-AM medications: $n=6$ ). Of the five reported adverse reactions with a suspected relation to AM medications, two reactions occurred in patients enrolled before March 2001 and these two patients were included in a detailed safety analysis of AM medications in the AMOS study. ${ }^{42}$ For reaction 1, the causal relationship to AM medication was confirmed (moderate injection-site reaction to Gencydo injections); for reaction 2, the causal relationship to AM medication was not confirmed (severe symptom aggravation following temporary dose reduction of conventional antiasthma medication). Reactions 3-5 occurred in patients enrolled after March 2001 and were not included in the safety analysis (reaction 3: mild symptom aggravation; reaction 4: moderate fever; reaction 5: moderate symptom aggravation). Adverse reactions from AM eurythmy/art/massage therapy were reported by one (3\%) of 30 therapy users. The reported reaction was an increased number of asthma attacks following AM art therapy with painting exercises. This reaction was of moderate intensity and did not require the painting exercises to be stopped.

Two serious adverse events occurred: One patient had surgery for life-threatening adhesive ileus, and one patient was acutely hospitalized for pneumonia. None of these events were causally related to any therapy or medication.

\section{Discussion}

The aim of this prospective cohort study was to obtain information on comprehensive AM therapy for asthma under routine outpatient conditions in Germany. Children and adults starting AM therapy for asthma were included: eight of nine patients used AM medications and one-fourth used eurythmy therapy. Under AM treatment, significant and sustained improvements of asthma symptoms and quality of life were observed.

Strengths of this study include a detailed assessment of the therapy setting and therapy-related factors, a long follow-up period, and high representativeness: 10\% of all AM-certified physicians seeing asthma patients in Germany participated; the participating AM physicians and therapists resembled all eligible physicians and therapists with respect to socio-demographic characteristics; and $95 \%$ of screened patients were enrolled. These features suggest that the study mirrors contemporary AM practice in office-based settings to a high degree.

To assess the routine clinical practice, where the selection of AM therapy options will vary according to individual needs, we analyzed AM as a whole system. ${ }^{34}$ Supplementary subgroup analyses were possible and showed significant improvements in patients receiving AM medical therapy, AM eurythmy/art/massage therapy, and eurythmy therapy alone. However, the sample size for AM art therapy and rhythmical massage therapy did not allow for separate analysis of these subgroups. The influence of other therapy variables (eg, duration of the consultation with the physician at study enrolment, number of AM therapy sessions) on clinical outcomes has been assessed in multivariate analyses of children ${ }^{47}$ and adults (submitted for publication) in AMOS with asthma and other chronic indications. 


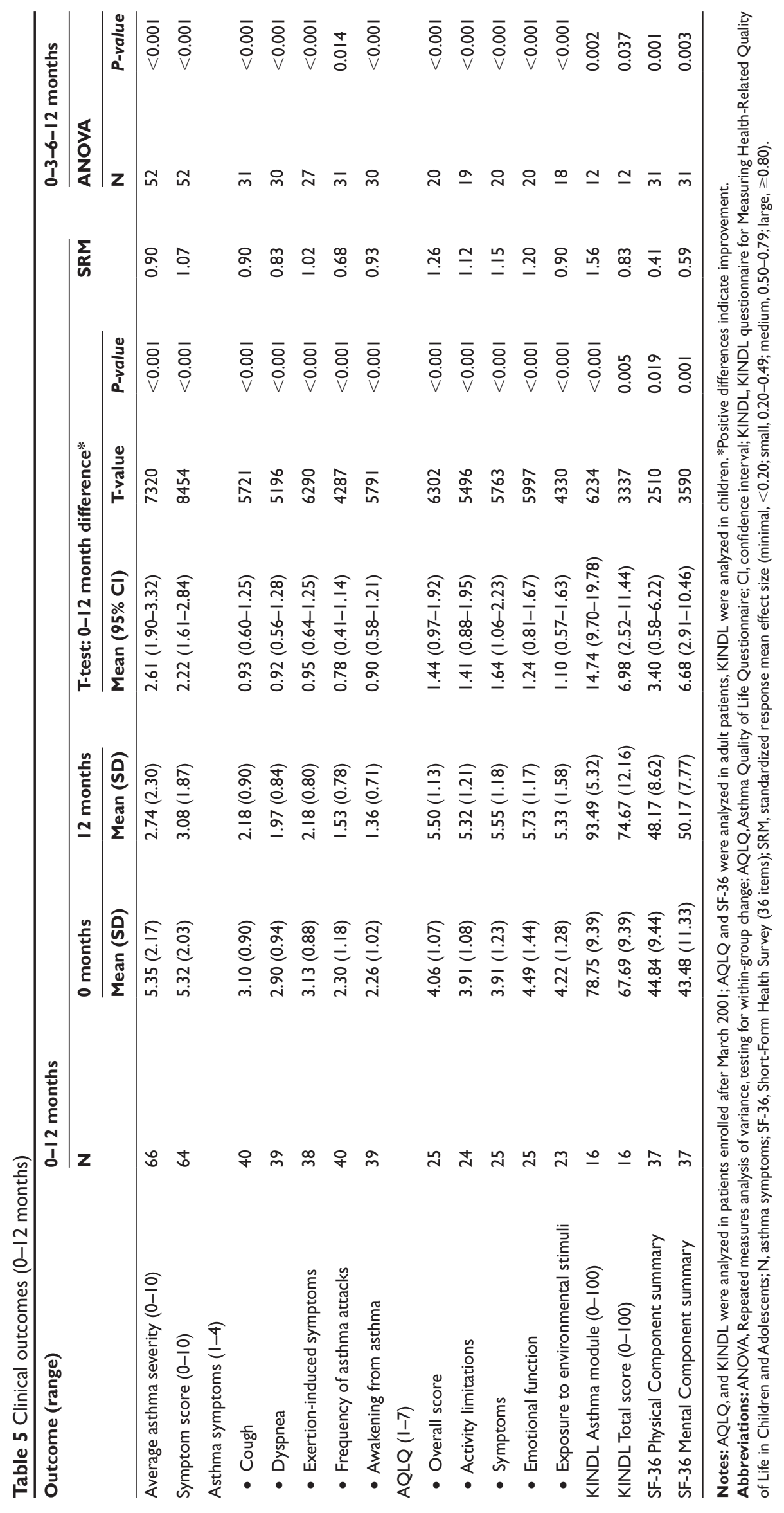


Average asthma severity

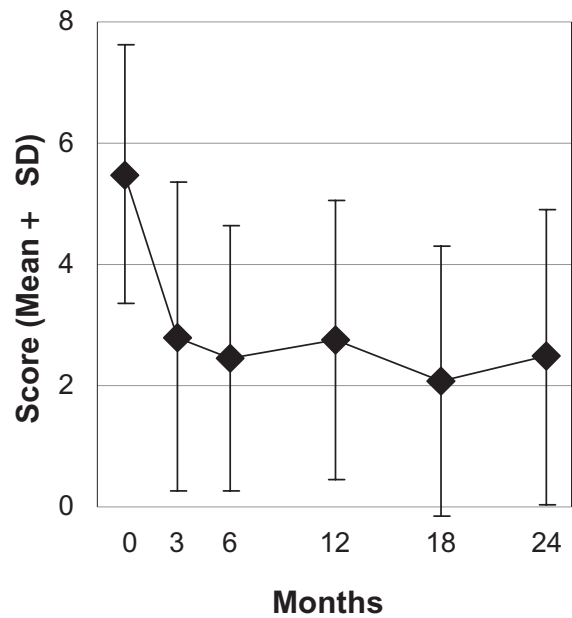

Figure I Average asthma severity and symptom score.

Notes: Range: 0 "not present" - 10 "worst possible", $\mathrm{n}=89$

Abbreviation: SD, standard deviation.

Inclusion criterion for this study was a clinical diagnosis of asthma. For logistical reasons it was not possible to have the diagnosis confirmed by performing pulmonary function tests on all patients prior to enrolment. However, in $98 \%$ of patients the physician classified the asthma diagnosis as 'definite' and in $92 \%$ the diagnosis had been confirmed by pulmonary function tests or by examination by pulmonologists (assessed in patients enrolled after March $2001,72 \%$ of the whole sample). A relevant confounding of the sample by inclusion of nonasthmatic subjects therefore seems unlikely.

Since the study had a long recruitment period, the study physicians were not able to participate throughout the period and to screen and enrol all eligible patients (criteria: see Methods section). For a different subset of patients from the AMOS project (patients referred to AM therapies for any chronic indication and enrolled before April 1st, 2001), it was estimated that physicians enrolled every fourth eligible patient. ${ }^{48}$ This selection could bias results if physicians were able to predict therapy response and if they preferentially screened and enrolled such patients for whom they expected a particularly favorable outcome. In this case one would expect the degree of selection (the proportion of eligible vs enrolled patients) to correlate positively with clinical outcomes. That was not the case, the correlation was almost zero $(-0.04)$. This analysis ${ }^{48}$ does not suggest that physicians' screening of eligible patients was affected by selection bias.

A limitation of the study is the absence of a comparison group receiving conventional treatment or no therapy.

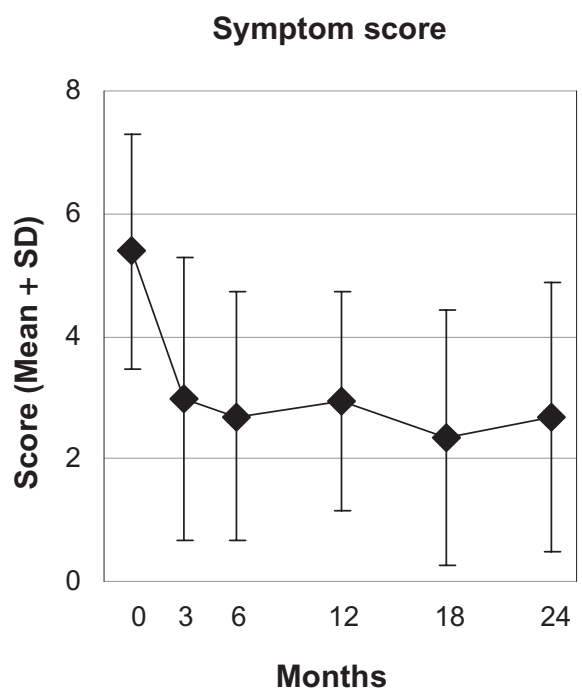

Accordingly, one must consider several other causes for the observed improvements apart from the AM treatment. We conducted a sensitivity analysis of average asthma severity, estimating the influence of attrition bias and adjunctive treatment with asthma medications or surgery. These two factors together explained up to $13 \%$ of the $0-12$ month improvement. Natural recovery from asthma appears unlikely in adult patients with long disease duration ${ }^{49}$ and $96 \%$ of adults had a disease duration of at least one year, but long-term natural recovery is not uncommon in children with asthma. ${ }^{50,51}$ Regression to the mean due to symptom fluctuation with preferential self-selection to therapy and study inclusion at symptom peaks is another possibility: according to a previous analysis of mixed diagnoses from the AMOS project, ${ }^{49}$ this phenomenon explained up to 0.43 points $(15 \%)$ of the $0-6$ month improvement of an outcome corresponding to average asthma severity in this analysis. Seasonal variations in asthma symptoms would be expected to be leveled out by analyzing outcomes at 12-month follow-up. Other possible confounders are psychological factors and nonspecific effects (eg, placebo effects, context effects, physician-patient interactions, patient expectations, social desirability effects). However, since AM therapy was evaluated as a whole system, ${ }^{34}$ the question of specific therapy effects vs nonspecific effects was not an issue of the present analysis. Nonetheless, the lack of objective outcomes, such as pulmonary function tests, to supplement the subjective outcomes is a limitation of the study. 

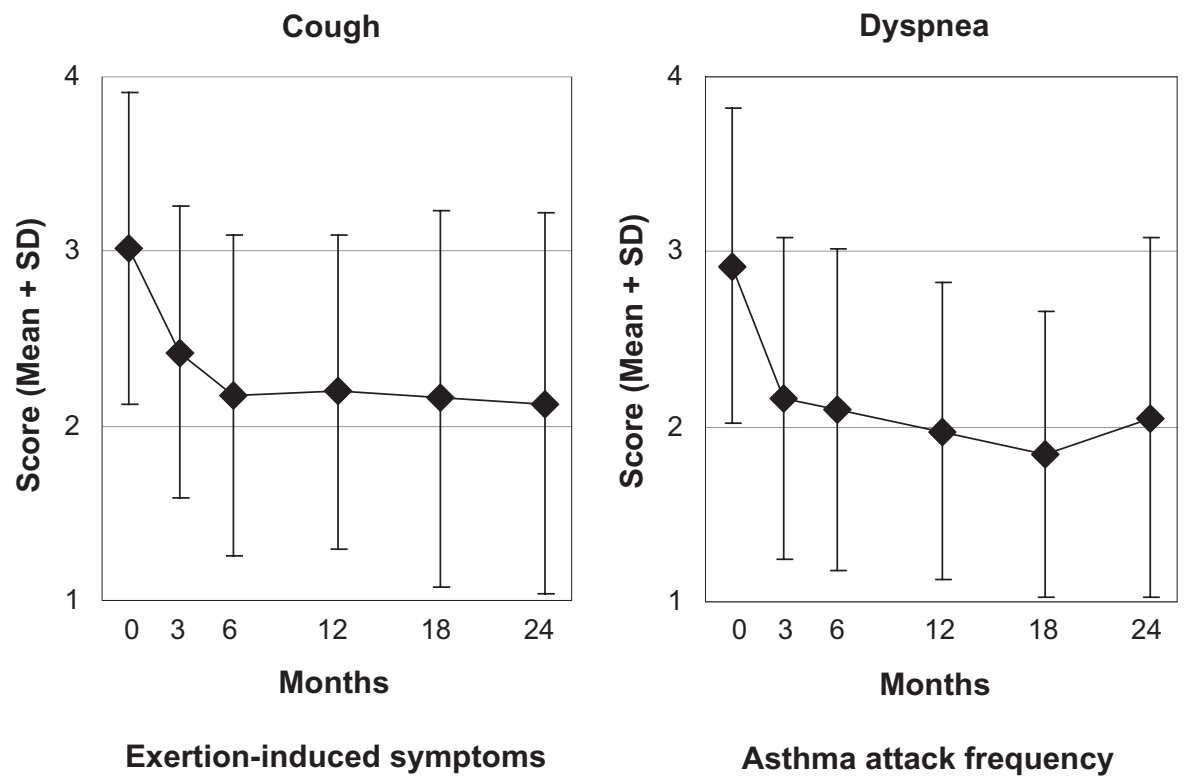

Asthma attack frequency
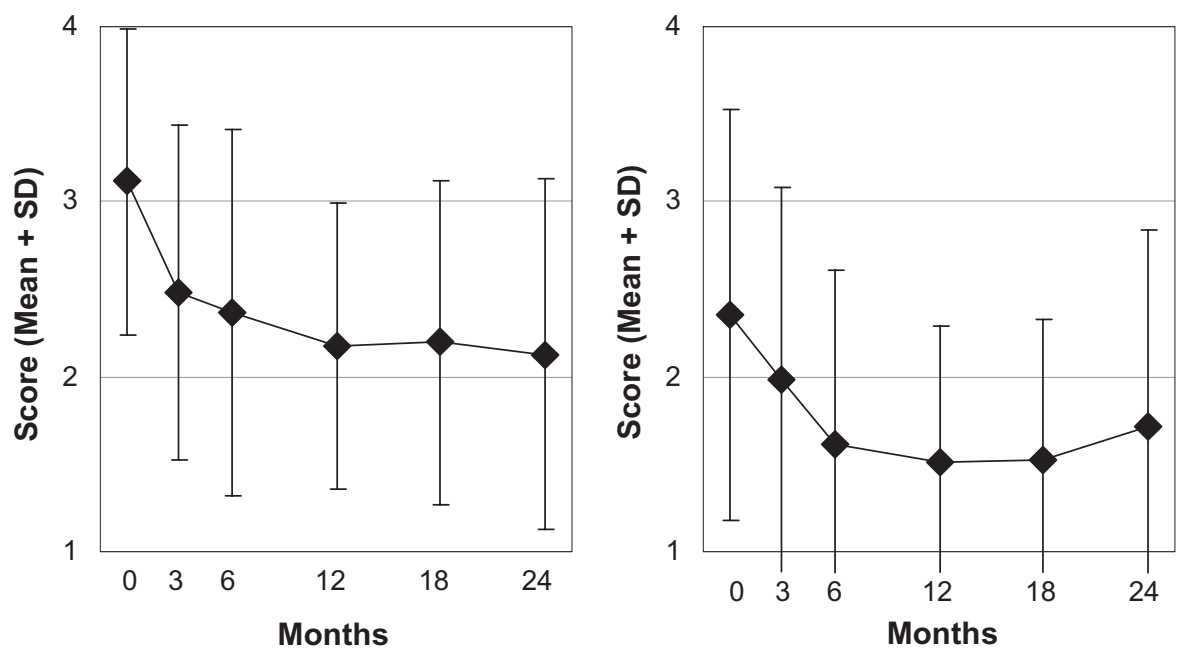

Awakening from asthma

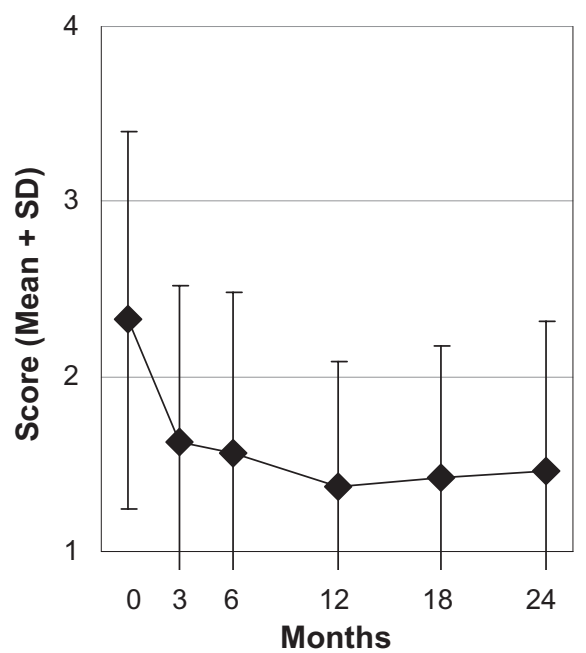

Figure 2 Asthma symptoms.

Notes: Likert scales, range I-4, higher scores indicate more symptoms (see Methods for details). Patients enrolled after March $200 \mathrm{I}, \mathrm{n}=62$. Abbreviation: SD, standard deviation. 

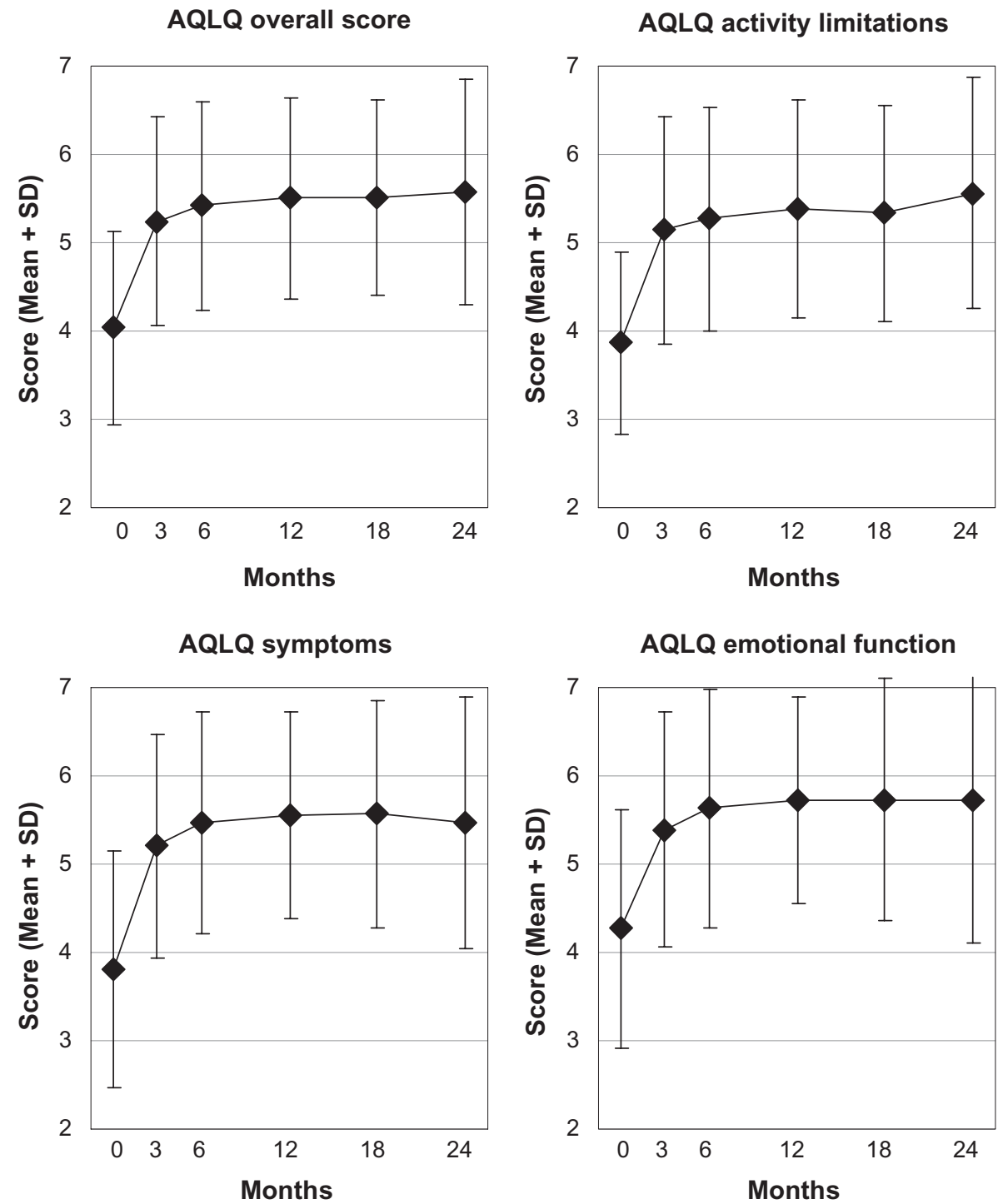

AQLQ environmental stimuli

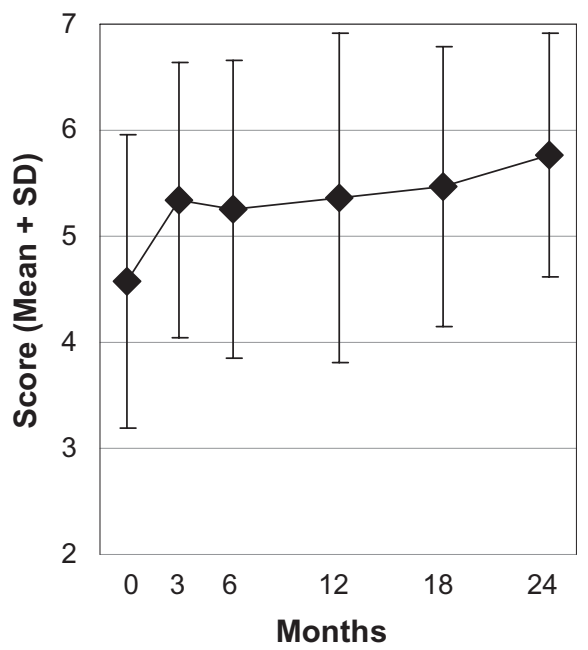

Figure 3 Asthma quality of life questionnaire.

Notes: Range: I, maximal impairment - 7, no impairment. ${ }^{38}$ Adult patients enrolled after March $200 \mathrm{I}, \mathrm{n}=39$.

Abbreviations: AQLQ, Asthma Quality of Life Questionnaire; SD, standard deviation. 
KINDL asthma module

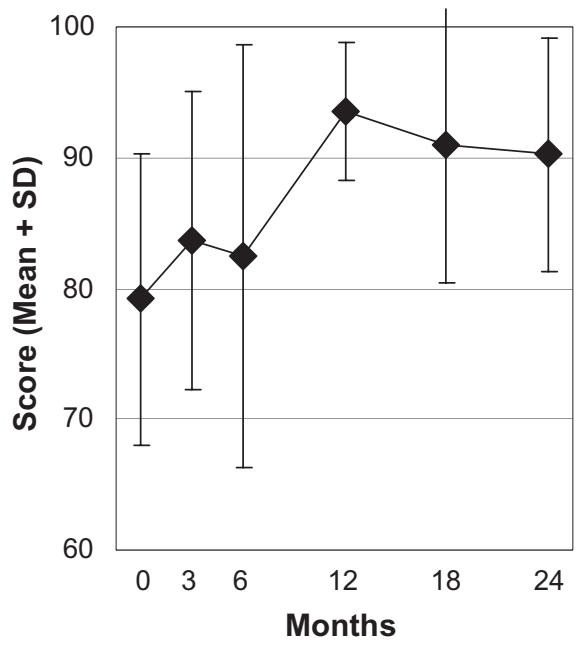

KINDL total quality of life

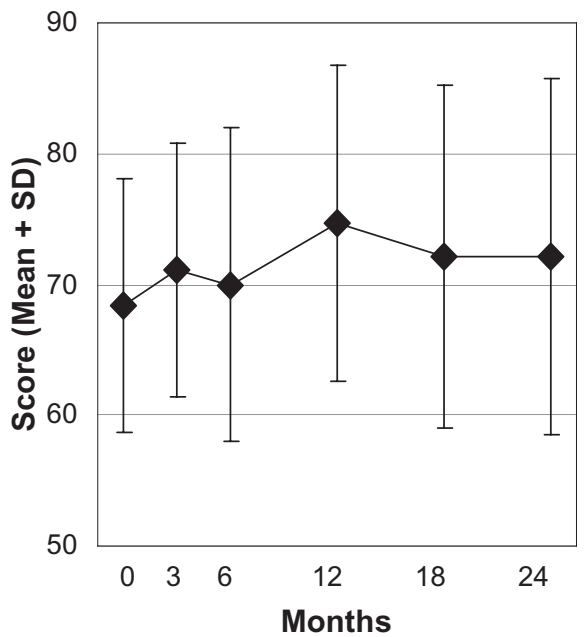

Figure $4 \mathrm{KINDL}$ asthma module and KINDL total quality of life.

Notes: Range 0-100, higher scores indicate better quality of life. ${ }^{41}$ Children aged 3-17 years, enrolled after March 2001 (age 3-7 years, parents' assessment; age 8-16 years, patients' assessment), $\mathrm{n}=23$.

Abbreviations: KINDL, Questionnaire for Measuring Health-Related Quality of Life in Children and Adolescents; SD, standard deviation.

This study comprised 16 outcome measures, each analyzed with two different methods at two follow-up assessments, a total of 64 analyses (Tables 5 and 7). We did not use $P$-value adjustment for multiple testing, which is a limitation in regard to the risk of finding significant results by chance (type-I-error). However, the problem of multiple testing has no universal solution, as $P$-value adjustment will increase the risk of making type-II errors. ${ }^{44}$ Another approach, used for the present analysis, is to have one single pre-defined primary outcome ${ }^{44}$ (average asthma severity at 12-month follow-up). Regarding secondary outcomes

SF-36 physical component

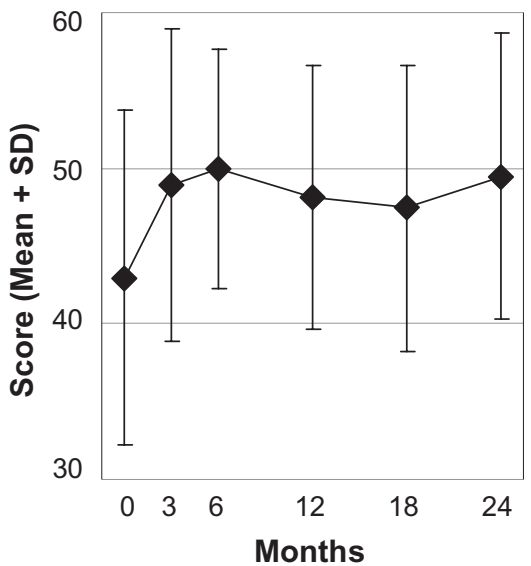

Figure 5 SF-36 Physical and Mental Component summary measures.

Notes: Higher scores indicate better health. Adult patients, $\mathrm{n}=53$.

Abbreviations: SD, standard deviation; SF-36, Short-Form Health Survey (36 items). (a total of 62 analyses), $59 P$-values indicated significant improvements and $43 P$-values were $<0.001$ - a constellation that would not be expected to occur by chance.

Apart from one analysis of 20 children, ${ }^{31}$ this study provides the first data on comprehensive AM treatment for asthma in Western European office-based settings. The predominance of women among adult study patients is in accordance with data from German primary care, ${ }^{52}$ while the proportion of patients who reported only intermittent asthma symptoms $(56 \%)$ was twice as high as in German primary care..$^{52,53}$ The low proportion of patients using inhaled corticosteroids 
Table 6 Average asthma severity 0-12 months: Subgroup and sensitivity analyses (SA)

\begin{tabular}{|c|c|c|c|c|c|}
\hline \multirow[t]{2}{*}{ Group/Analysis } & \multirow[t]{2}{*}{$\mathbf{N}$} & \multirow{2}{*}{$\frac{0 \text { months }}{\text { Mean (SD) }}$} & \multirow{2}{*}{$\frac{12 \text { months }}{\text { Mean (SD) }}$} & \multicolumn{2}{|c|}{ T-test: $0-12$ month difference } \\
\hline & & & & Mean $(95 \% \mathrm{Cl})$ & $P$-value \\
\hline $\begin{array}{l}\text { Main analysis: Patients with available } \\
\text { data at } 0 \text { and } 12 \text { months }\end{array}$ & 66 & $5.35(2.17)$ & $2.74(2.30)$ & $2.61(1.90-3.32)$ & $<0.001$ \\
\hline \multicolumn{6}{|l|}{ Age groups } \\
\hline - Children (2-16 years) & 29 & $5.69(2.24)$ & $2.14(2.07)$ & $3.55(2.45-4.65)$ & $<0.001$ \\
\hline - Adults ( $17-70$ years) & 37 & $5.08(2.11)$ & $3.22(2.39)$ & $1.86(0.96-2.76)$ & $<0.001$ \\
\hline \multicolumn{6}{|l|}{ Main anthroposophic therapy modality } \\
\hline - Medical & 37 & $5.35(2.15)$ & $2.35(1.99)$ & $3.00(2.17-3.83)$ & $<0.001$ \\
\hline $\begin{array}{l}\text { - Eurythmy therapy, art therapy, or } \\
\text { rhythmical massage therapy }\end{array}$ & 29 & $5.34(2.24)$ & $3.24(2.60)$ & $2.10(0.84-3.37)$ & 0.002 \\
\hline - Eurythmy therapy & 21 & $5.19(2.36)$ & $3.14(2.63)$ & $2.05(0.57-3.53)$ & 0.009 \\
\hline \multicolumn{6}{|l|}{ Number of patients enrolled per physician } \\
\hline - I-5 patients (30 physicians) & 44 & $5.43(2.14)$ & $2.98(2.34)$ & $2.45(1.52-3.39)$ & $<0.001$ \\
\hline - 36 patients (one physician) & 22 & $5.18(2.28)$ & $2.27(2.21)$ & $2.91(1.80-4.02)$ & $<0.001$ \\
\hline SAI: Last value carried forward & 89 & $5.48(2.14)$ & $3.20(2.5 \mathrm{I})$ & $2.28(1.69-2.87)$ & $<0.001$ \\
\hline $\begin{array}{l}\text { SA2: Patients not using asthma medications } \\
\text { apart from adrenergic inhalants, and } \\
\text { not having asthma-related surgery in } \\
\text { months } 0-12\end{array}$ & 28 & $5.93(2.05)$ & $3.39(2.77)$ & $2.54(1.26-3.81)$ & $<0.001$ \\
\hline $\mathrm{SA} 1+\mathrm{SA} 2$ & 28 & $5.93(2.05)$ & $3.39(2.77)$ & $2.54(1.26-3.81)$ & $<0.001$ \\
\hline
\end{tabular}

Abbreviations: $\mathrm{Cl}$, confidence interval; SD, standard deviation.

$(30 \%)$ or any conventional antiasthma-medications $(58 \%)$ in months $0-12$ could be related to the low self-reported asthma severity. Furthermore, both asthma severity (assessed by symptom frequency) and medication use may have been under-reported due to recall bias..$^{54}$ The daily dosage of inhaled corticosteroids was not documented and can therefore not be compared to other studies.

In adult patients, asthma-related quality of life at baseline, assessed with the AQLQ overall score (4.0 points), was one-third standard deviation worse than average in a German multicenter primary care cohort of asthma patients (4.4 points). ${ }^{53}$ In this multicenter cohort, AQLQ overall score showed an inverse relation to asthma severity, with the baseline score value of the present study (4.0 points) falling between scores of patients with mild persistent ( 3.8 points) and moderate persistent asthma (4.6 points). In months 0-12 of the present study, AQLQ overall score showed an improvement of 1.4 points, which is classified as a moderate improvement (1.0-1.5 points).$^{39}$ In other evaluable asthma cohorts receiving other treatments, the corresponding 0-12 month improvements were moderate, ${ }^{4,55-57}$ minimal $(0.5-1.0 \text { points })^{57-59}$ or not relevant $(<0.5$ points $){ }^{60-62}$ In adult patients of the present study, generic quality of life, assessed with the SF-36 Health Survey, was similar to other asthma cohorts at baseline and improved similarly during follow-up. ${ }^{63}$ In children of the present study, generic quality of life at baseline, assessed with the KINDL total quality of life score, was two-third standard deviations worse than average score values in German children with asthma. ${ }^{64}$ In months $0-12$ of this study the KINDL total quality of life score improved similarly to $0-12$ month improvements in asthma cohorts receiving other treatment, ${ }^{65,66}$ while KINDL asthma module was similar at baseline but showed more outspoken improvement in this study than in a cohort of children undergoing inpatient rehabilitation (difference of 0.9 standard deviations). ${ }^{67}$ To sum up: relative to other studies, our study patients had low self-reported asthma symptom severity but similar or more outspoken reduction of quality of life at baseline. One consequence of the predominantly low symptom severity is that study results may not be generalizable to patients with high asthma severity. A low correlation between asthma symptoms and quality of life has been found in many studies. ${ }^{68}$ Quality of life improvements in our study were at least of the same order of magnitude as in other treated cohorts. Since data on airway caliber were not available in our study, a comparison to other studies is not possible.

Previous studies have found beneficial effects of AM medications ${ }^{28,29}$ or comprehensive AM therapy ${ }^{30,31}$ in children $^{30,31}$ or adults ${ }^{28,29}$ with asthma. In accordance with these findings, our multicenter study showed sustained 


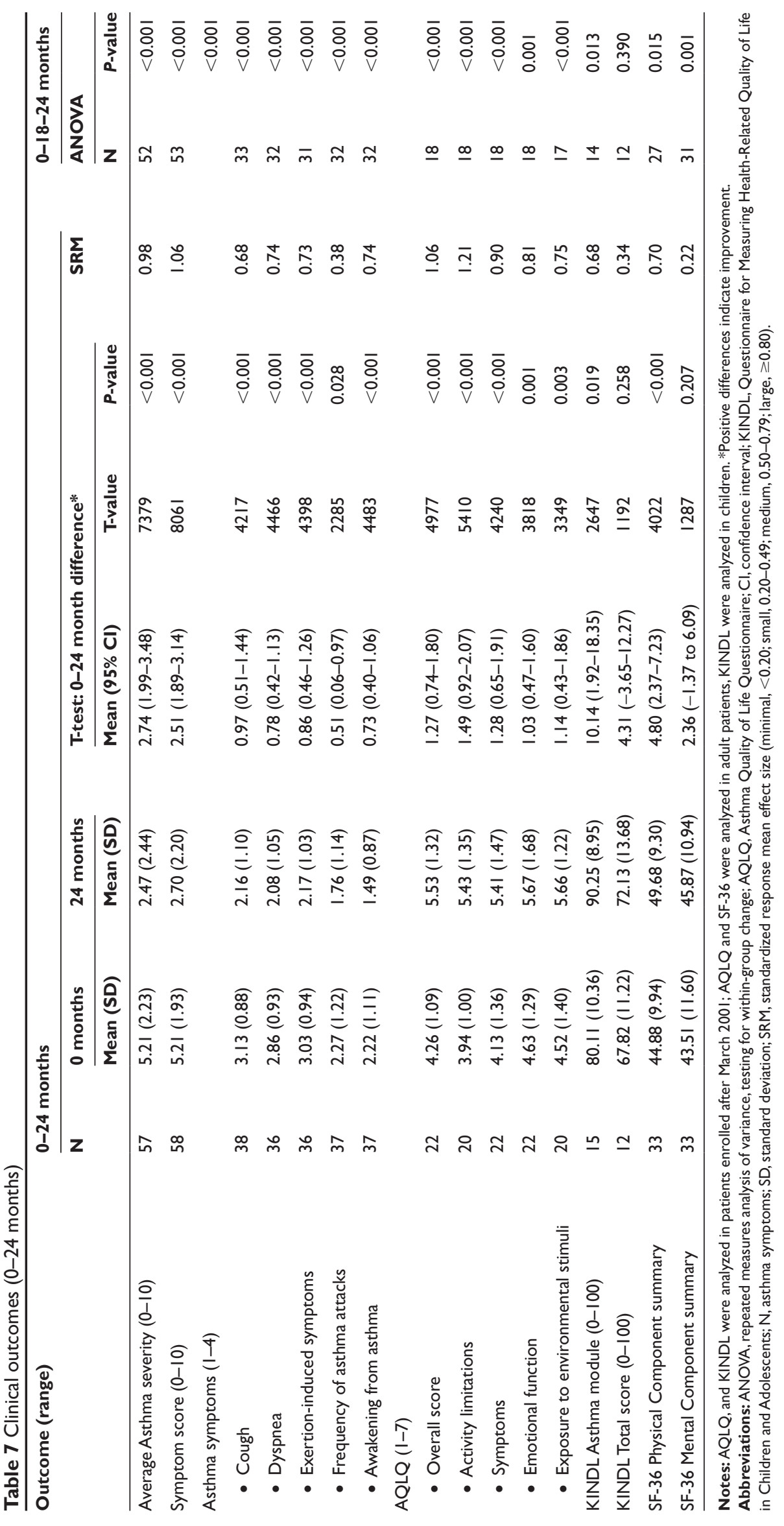


improvement of asthma symptoms as well as generic and asthma-related quality of life in children and in adults under comprehensive AM treatment.

The AM approach evaluated in this study differs from many other therapies used for asthma in two aspects: Whereas in many complementary ${ }^{6,69}$ and conventional therapies the patient is essentially a passive user of products (eg, herbs, conventional medications) or recipient of treatments (eg, acupuncture), the AM approach involves active as well as passive therapies. Whereas other active therapies (eg, relaxation techniques) may be perceived as monotonous, the AM exercise therapies used by more than one-third of patients in this study allow for artistic movements (eurythmy) or expression (eg, painting, music), which may be welcome in some patients. Another favorable aspect of AM is its full integration with conventional medicine, allowing for the provision of all conventional and complementary treatment by one medical practitioner, thus avoiding communication difficulties and conflicts about disclosure of complementary treatment to providers of conventional asthma therapy. ${ }^{69}$

Future studies on AM treatment for asthma should include pulmonary function tests and a more detailed documentation of the AM therapy modalities (eg, for eurythmy therapy: the type of eurythmy exercises used and the frequency and duration of eurythmy home exercises). Studies with concurrent control groups would be desirable. However, it is difficult to conduct randomized trials in AM settings, as randomization is often rejected by AM physicians and their patients, chiefly due to strong therapy preferences. ${ }^{21,22}$ One possible solution could be to recruit patients from outside AM settings and randomize them to immediate treatment in an AM setting or to a waiting-list control group. ${ }^{70}$ Another possibility would be a nonrandomized system comparison of treatment by AM and conventional physicians with adjustment for baseline differences. ${ }^{71}$

\section{Conclusion}

Patients with asthma under AM treatment had long-term improvements of symptoms as well as asthma-related and generic quality of life. The improvements in quality of life scores were at least of the same order of magnitude as in asthma cohorts receiving other treatment. These findings are encouraging and warrant further research.

\section{Disclosure}

Within the last five years $\mathrm{HJH}$ and GSK have received restricted research grants from Wala-Heilmittel GmbH and
Weleda AG, manufacturers of AM medications. Otherwise all authors declare that they have no competing interests.

This study was funded by the Software-AG Stiftung and the Innungskrankenkasse Hamburg, with supplementary grants from the Helixor Stiftung, the Mahle Stiftung, and the Zukunftsstiftung Gesundheit. The sponsors had no influence on design and conduct of the study; collection, management, analysis or interpretation of the data; or preparation, review or approval of the manuscript. Our special thanks go to the study physicians, therapists, and patients for participating.

HJH, CMW, GSK, SNW, and HK contributed to study design. HJH, AG, CS, and HK contributed to data collection. $\mathrm{HJH}, \mathrm{RZ}$, and HK wrote the analysis plan, and $\mathrm{HJH}$ and AG analyzed data. HJH was principal author of the paper, had full access to all data, and is guarantor. All authors contributed to manuscript drafting and revision and approved the final manuscript.

\section{References}

1. Braman SS. The global burden of asthma. Chest. 2006;130(1 Suppl): 4S-12S.

2. Masoli M, Fabian D, Holt S, Beasley R. Global burden of asthma. Wellington, New Zealand: Global Initiative for Asthma; 2004.

3. Scott KM, Von KM, Ormel J, et al. Mental disorders among adults with asthma: results from the World Mental Health Survey. Gen Hosp Psychiatry. 2007;29(2):123-133.

4. Bateman ED, Boushey HA, Bousquet J, et al. Can guideline-defined asthma control be achieved? The Gaining Optimal Asthma ControL study. Am J Respir Crit Care Med. 2004;170(8):836-844.

5. Szefler SJ, Mitchell H, Sorkness CA, et al. Management of asthma based on exhaled nitric oxide in addition to guideline-based treatment for inner-city adolescents and young adults: a randomised controlled trial. Lancet. 2008;372(9643):1065-1072.

6. Slader CA, Reddel HK, Jenkins CR, Armour CL, Bosnic-Anticevich SZ. Complementary and alternative medicine use in asthma: who is using what? Respirology. 2006;11(4):373-387.

7. Steiner R, Wegman I. Extending practical medicine. Fundamental principles based on the science of the spirit. [GA 27] [First published 1925]. Bristol, UK: Rudolf Steiner Press; 2000.

8. Derzeitige Ausbreitung der Anthroposophisch-Medizinischen Bewegung [Current Dissemination of the Anthroposophic Medical Movement]. 1924-2004 Sektion für Anthroposophische Medizin. Standortbestimmung/ Arbeitsperspektiven. [1924-2004 Section for Anthroposophic Medicine. Current status and future perspectives]. Dornach, Switzerland: Free Academy of Spiritual Science; 2004. p. 7-9.

9. Fintelmann V. Intuitive Medizin. Einführung in eine anthroposophisch ergänzte Medizin. [Intuitive Medicine. Introduction to anthroposophically extended medicine] 3rd ed. Stuttgart, Germany: Hippokrates Verlag; 1995.

10. Girke M. Erkrankungen der Atmungsorganisation - Asthma bronchiale [Respiratory diseases - Bronchial asthma]. Der Merkurstab. 1998; 50(5):281-289.

11. Ecker D, Bräuner-Gülow G. Anthroposophische Asthmatherapie und-schulung bei Kindern [Anthroposophic asthma therapy and training in children]. Der Merkurstab. 1999;52(2):88-95.

12. Ritchie J, Wilkinson J, Gantley M, Feder G, CarterY, Formby J. A model of integrated primary care: anthroposophic medicine. London, UK: Department of General Practice and Primary Care, St. Bartholomew's and the Royal London School of Medicine, Queen Mary, University of London; 2001. 
13. Schnürer C. Asthma bronchiale [Bronchial asthma]. Esslingen, Germany: Gesundheitspflege Initiativ; 2000.

14. Soldner G, Stellmann HM. Individuelle Pädiatrie: Leibliche, seelische und geistige Aspekte in Diagnostik und Beratung. Anthroposophischhomöopathische Therapie [Individualised pediatrics: somatic, psychological and spiritual aspects of diagnostics and counselling. Anthroposophic-homeopathic therapy]. 3rd ed. Stuttgart, Germany: Wissenschaftliche Verlagsgesellschaft; 2007.

15. Majorek M, Tüchelmann T, Heusser P. Therapeutic Eurythmy-movement therapy for children with attention deficit hyperactivity disorder (ADHD): a pilot study. Complement Ther Nurs Midwifery. 2004;10(1):46-53.

16. Hamre HJ, Witt CM, Glockmann A, Ziegler R, Willich SN, Kiene H. Eurythmy therapy in chronic disease: a four-year prospective cohort study. BMC Public Health. 2007;7:61.

17. Pütz H. Leitlinie zur Behandlung mit Anthroposophischer Kunsttherapie $(B V A K T)^{\circledR}$ für die Fachbereiche Malerei, Musik, Plastik, Sprachgestaltung [Guideline for treatment with Anthroposophic Art Therapy with the therapy modalities painting, music, clay, speech]. Filderstadt, Germany: Berufsverband für Anthroposophische Kunsttherapie e. V. [Association for Anthroposophic Art Therapy in Germany]; 2008.

18. Hamre HJ, Witt CM, Glockmann A, Ziegler R, Willich SN, Kiene H. Rhythmical massage therapy in chronic disease: a 4-year prospective cohort study. J Altern Complement Med. 2007;13(6):635-642.

19. Simon L. Prescribing anthroposophic medicines: Substances, Pharmaceutical processes, principle of effectiveness. Der Merkurstab - Journal of Anthroposophic Medicine (Supplement: Vademecum of Anthroposophic Medicines First English edition). 2009;62 [CD-ROM].

20. International Association of Anthroposophic Pharmacists. Anthroposophic Pharmaceutical Codex APC, Second Edition. Dornach, Switzerland: The International Association of Anthroposophic Pharmacists (IAAP); 2007.

21. Kienle GS, Kiene H, Albonico HU. Anthroposophic Medicine: Effectiveness, utility, costs, safety. Stuttgart, Germany: Schattauer Verlag; 2006.

22. Hamre HJ, Kiene H, Kienle GS. Clinical research in anthroposophic medicine. Altern Ther Health Med. 2009;15(6):52-55.

23. Council for Curative Education and Social Therapy. List of centers. Dornach, Switzerland: Council for Curative Education and Social Therapy; 2009.

24. Waldorfschulen Weltweit [Waldorf Schools Worldwide]. Stuttgart, Germany: Bund der Freien Waldorfschulen; 2009.

25. Alm JS, Swartz J, Lilja G, Scheynius A, Pershagen G. Atopy in children of families with an anthroposophic lifestyle. Lancet. 1999;353(9163):1485-1488.

26. Floistrup H, Swartz J, Bergstrom A, et al. Allergic disease and sensitization in Steiner school children. J Allergy Clin Immunol. 2006;117(1):59-66.

27. Alm JS, Swartz J, Björksten B, et al. An anthroposophic lifestyle and intestinal microflora in infancy. Pediatr Allergy Immunol. 2002;13(6): 402-411.

28. Kaliks B, Neves P. Tratamento da asma bronciquica com remedios da medicina antroposopfica [Treatment of bronchial asthma with anthroposophic medications]. Revista Ampliacao da Arte Medica. 1994:6-8.

29. Koshetchkin DV. Application of some complex fitotherapeutic and homeopathic means in treatment of the bronchial asthma patients [abstract]. St. Petersburg, Russian Federation: St. Petersburg Medical University; 1999.

30. Ecker D, Uithoven MA, van Dijk HA. Anthroposophische Asthmatherapie im Vergleich. Ersetzt sie das inhalative Corticoid? [Anthroposophical asthma therapy: A comparison. Is it as good as inhalative corticosteroids?]. Schweiz Z Ganzheitsmedizin. 2001;13(6):326-334.

31. Andriashvili L, Karseladze R, Ulrich B. Anthroposophische Behandlungsaspekte des Asthma bronchiale im Kindesalter [Anthroposophic aspects of bronchial asthma treatment in childhood]. Georgian Med News. 2007;(144):43-48.
32. Hamre HJ, Becker-Witt C, Glockmann A, Ziegler R, Willich SN, Kiene H. Anthroposophic therapies in chronic disease: The Anthroposophic Medicine Outcomes Study (AMOS). Eur J Med Res. 2004;9(7):351-360.

33. Hamre HJ, Witt CM, Glockmann A, Ziegler R, Willich SN, Kiene H. Health costs in anthroposophic therapy users: a two-year prospective cohort study. BMC Health Serv Res. 2006;6:65.

34. Boon H, MacPherson H, Fleishman S, et al. Evaluating complex healthcare systems: a critique of four approaches. Evid Based Complement Alternat Med. 2007;4(3):279-285.

35. Westhoff G. VAS Visuelle Analog-Skalen; auch VAPS Visual Analogue Pain Scales, NRS Numerische Rating-Skalen; Mod. Kategorialskalen [VAS Visual Analogue Scales; also VAPS Visual Analogue Pain Scales, NRS Numerical Rating Scales; Mod. Categorical Scales; Mod.]. Handbuch psychosozialer Messinstrumente. Göttingen, Germany: Hogrefe; 1993. p. 881-885.

36. Wjst M, Wichmann HE. Collaborative study on the genetics of asthma in Germany. Clin Exp Allergy. 1995;25(Suppl 2):23-25.

37. Weiland SK, von Mutius E, Keil U; für das ISAAC Steering Committee. Die International Study of Asthma and Allergies in Childhood (ISAAC): Forschungsstrategie, Methoden und Ausblick [The International Study of Asthma and Allergies in Childhood (ISAAC): rationale, methods and outlook]. Allergologie. 1999;5:275-282.

38. Juniper EF, Guyatt GH, Ferrie PJ, Griffith LE. Measuring quality of life in asthma. Am Rev Respir Dis. 1993;147(4):832-838.

39. Juniper EF, Guyatt GH, Willan A, Griffith LE. Determining a minimal important change in a disease-specific quality of life questionnaire. J Clin Epidemiol. 1994;47(1):81-87.

40. Bullinger M, Kirchberger I. SF-36 Fragebogen zum Gesundheitszustand. Handanweisung. [SF-36 Health Survey, German Version: Handbook]. Göttingen, Germany: Hogrefe-Verlag; 1998.

41. Ravens-Sieberer U, Bullinger M. KINDL ${ }^{\circledR}$ English. Questionnaire for Measuring Health-Related Quality of Life in Children and Adolescents. Revised Version. Manual. Berlin, Germany: Robert Koch Institute; 2000.

42. Hamre HJ, Witt CM, Glockmann A, Tröger W, Willich SN, Kiene H. Use and safety of anthroposophic medications in chronic disease: a 2-year prospective analysis. Drug Saf. 2006;29(12):1173-1189.

43. Girden ER. ANOVA Repeated Measures. Newbury Park, CA: Sage Publications; 1992.

44. Feise RJ. Do multiple outcome measures require p-value adjustment? BMC Med Res Methodol. 2002;2:8.

45. Cohen J. Statistical Power Analysis for the Behavioral Sciences. 2nd ed. Hillsdale, NJ: Lawrence Erlbaum; 1988.

46. McDowell I. Measuring Health. A guide to rating scales and questionnaires. 2nd ed. Oxford, UK: Oxford University Press; 2006.

47. Hamre HJ, Witt CM, Kienle GS, et al. Anthroposophic therapy for children with chronic disease: a two-year prospective cohort study in routine outpatient settings. BMC Pediatr. 2009;9:39.

48. Hamre HJ, Witt CM, Glockmann A, Ziegler R, Willich SN, Kiene H. Anthroposophic therapy for chronic depression: a four-year prospective cohort study. BMC Psychiatry. 2006;6:57.

49. Hamre HJ, Glockmann A, Kienle GS, Kiene H. Combined bias suppression in single-arm therapy studies. $J$ Eval Clin Pract. 2008;14(5):923-929.

50. Reed CE. The natural history of asthma. J Allergy Clin Immunol. 2006;118(3):543-548.

51. Panettieri RA Jr, Covar R, Grant E, Hillyer EV, Bacharier L. Natural history of asthma: persistence versus progression-does the beginning predict the end? J Allergy Clin Immunol. 2008;121(3):607-613.

52. Vermeire PA, Rabe KF, Soriano JB, Maier WC. Asthma control and differences in management practices across seven European countries. Respir Med. 2002;96(3):142-149.

53. Schneider A, Lowe B, Meyer FJ, Biessecker K, Joos S, Szecsenyi J. Depression and panic disorder as predictors of health outcomes for patients with asthma in primary care. Respir Med. 2008;102(3):359-366.

54. Evans C, Crawford B. Patient self-reports in pharmacoeconomic studies. Their use and impact on study validity. Pharmacoeconomics. 1999;15(3):241-256. 
55. SelfT, Rumbak MJ, Kelso T, et al. Does salmeterol facilitate "step-down" therapy in patients with asthma receiving moderate to high doses of inhaled corticosteriods? Curr Ther Res Clin Exp. 1998;59(11):803-811.

56. Price DB, Williams AE, Yoxall S. Salmeterol/fluticasone stable-dose treatment compared with formoterol/budesonide adjustable maintenance dosing: impact on health-related quality of life. Respir Res. 2007;8:46.

57. Cox G, Thomson NC, Rubin AS, et al. Asthma control during the year after bronchial thermoplasty. $N$ Engl J Med. 2007;356(13): 1327-1337.

58. Juniper EF, Svensson K, O’Byrne PM, et al. Asthma quality of life during 1 year of treatment with budesonide with or without formoterol. Eur Respir J. 1999;14(5):1038-1043.

59. Juniper EF, Price DB, Stampone PA, Creemers JP, Mol SJ, Fireman P. Clinically important improvements in asthma-specific quality of life, but no difference in conventional clinical indexes in patients changed from conventional beclomethasone dipropionate to approximately half the dose of extrafine beclomethasone dipropionate. Chest. 2002;121(6):1824-1832.

60. Moudgil H, Marshall T, Honeybourne D. Asthma education and quality of life in the community: a randomised controlled study to evaluate the impact on white European and Indian subcontinent ethnic groups from socioeconomically deprived areas in Birmingham, UK. Thorax. 2000;55(3):177-183.

61. Green RH, Brightling CE, McKenna S, et al. Asthma exacerbations and sputum eosinophil counts: a randomised controlled trial. Lancet. 2002;360(9347):1715-1721.

62. Tierney WM, Overhage JM, Murray MD, et al. Can computer-generated evidence-based care suggestions enhance evidence-based management of asthma and chronic obstructive pulmonary disease? A randomized, controlled trial. Health Serv Res. 2005;40(2):477-497.

63. Hamre HJ, Glockmann A, Tröger W, Kienle GS, Kiene H. Assessing the order of magnitude of outcomes in single-arm cohorts through systematic comparison with corresponding cohorts: an example from the AMOS study. BMC Med Res Methodol. 2008;8:11.

64. Ravens-Sieberer U, Ellert U, Erhart M. Gesundheitsbezogene Lebensqualität von Kindern und Jugendlichen in Deutschland. Eine Normstichprobe für Deutschland aus dem Kinder- und Jugendgesundheitssurvey (KIGGS) [Health-related quality of life of children and adolescents in Germany. Norm data from the German Health Interview and Examination Survey (KiGGS)]. Bundesges Gesundheitsforsch Gesundheitsschutz. 2007;50(5-6):810-818.

65. Runge C, Lecheler J, Horn M, Tews JT, Schaefer M. Outcomes of a Web-based patient education program for asthmatic children and adolescents. Chest. 2006;129(3):581-593.

66. Bullinger M, Ravens-Sieberer U. Lebensqualität und chronische Krankheit: die Perspektive von Kindern und Jugendlichen in der Rehabilitation [Quality of life and chronic conditions: the perspective of children and adolescents in rehabilitation]. Prax Kinderpsychol Kinderpsychiatr. 2006;55(1):23-35.
67. Ravens-Sieberer U, Redegeld M, Bauer CP, et al. Lebensqualität chronisch kranker Kinder und Jugendlicher in der Rehabilitation [Quality of life of children and adolescents in inpatient rehabilitation]. Zeitschrift für medizinische Psychologie. 2005;14(1):5-12.

68. Juniper EF, Wisniewski ME, Cox FM, Emmett AH, Nielsen KE, O'Byrne PM. Relationship between quality of life and clinical status in asthma: a factor analysis. Eur Respir J. 2004;23(2):287-291.

69. Shaw A, Noble A, Salisbury C, Sharp D, Thompson E, Peters TJ. Predictors of complementary therapy use among asthma patients: results of a primary care survey. Health Soc Care Community. 2008;16(2):155-164.

70. Steinsbekk A, Fonnebo V, Lewith G, Bentzen N. Homeopathic care for the prevention of upper respiratory tract infections in children: a pragmatic, randomised, controlled trial comparing individualised homeopathic care and waiting-list controls. Complement Ther Med. 2005;13(4):231-238.

71. Hamre HJ, Fischer M, Heger M, et al. Anthroposophic vs conventional therapy of acute respiratory and ear infections: a prospective outcomes study. Wien Klin Wochenschr. 2005;117(7-8):256-268.

72. Brauns H, Steinmann H. Educational Reform in France, West-Germany and the United Kingdom: updating the CASMIN educational classification. Mannheim, Germany: Mannheimer Zentrum für Europäische Sozialforschung; 1997.

73. Bundesgesundheitssurvey 1998. Public Use File [Federal Health Survey 1998. Public Use File]. Berlin, Germany: Robert Koch Institute; 2000.

74. Federal Statistical Office. Statistical Yearbook for the Federal Republic of Germany. Stuttgart, Germany: Metzler-Poeschel Verlag; 2001.

75. Hoffmeister H, Schelp FP, Mensink GB, Dietz E, Bohning D. The relationship between alcohol consumption, health indicators and mortality in the German population. Int J Epidemiol. 1999;28(6):1066-1072.

76. Junge B, Nagel M. Das Rauchverhalten in Deutschland. [Smoking behavior in Germany]. Gesundheitswesen. 1999;61(Sonderheft 2): S121-S125.

77. Breckenkamp J, Laaser U, Danell T. Freizeitinteressen und subjektive Gesundheit. [Hobbies and Subjective Health]. Wiesbaden, Germany: Federal Institute for Population Research at the Federal Statistical Office; 2001.

78. VDR Statistik Rentenbestand am 31. Dezember 2000. [VDR-Statistics of Pensioners on December 31, 2000]. Berlin, Germany: Association of German Pension Insurance Companies; 2005.

79. Bergmann E, Ellert U. Sehhilfen, Hörhilfen und Schwerbehinderung. [Seeing aids, hearing aids, and disabilities]. Bundesgesundheitsblatt. 2000;(6):432.

80. Ministry of Health and Social Welfare. Arbeitsunfähigkeits-, Krankengeld- und Krankenhausfälle und-tage nach der GKV-Statistik KG2 1996 bis 2002. [Number of cases and days with sick leave and with inpatient hospitalisation, according to the statistics of the Statutory Health Insurance KG2, 1996 to 2002]. Bonn, Germany: Ministry of Health and Social Welfare; 2003.

\section{Publish your work in this journal}

The Journal of Asthma and Allergy is an international, peer-reviewed open-access journal publishing original research, reports, editorials and commentaries on the following topics: Asthma; Pulmonary physiology; Asthma related clinical health; Clinical immunology and the immunological basis of disease; Pharmacological interventions and

\section{Dovepress}

new therapies. Issues of patient safety and quality of care will also be considered. The manuscript management system is completely online and includes a very quick and fair peer-review system, which is all easy to use. Visit http://www.dovepress.com/testimonials.php to read real quotes from published authors. 